\title{
Comparative Evaluation of Diabetes in Pregnancy Study Group of India and International Association of Diabetes and Pregnancy Study Groups: Criteria for the Diagnosis of Gestational Diabetes Mellitus
}

\author{
Amrita Singh ${ }^{1}$, Richa Yadav ${ }^{2}$, Shipra Kunwar ${ }^{3}$, Shweta Kumari ${ }^{4}$, Kumkum Shrivastava $^{5}$
}

\begin{abstract}
Introduction: Gestational diabetes mellitus (GDM) is a glucose tolerance disorder that occurs or is diagnosed for the first time during pregnancy. GDM affects $1-14 \%$ of all pregnancies, and its incidence has been steadily rising. GDM is a major cause of perinatal morbidity and mortality, as well as maternal morbidity. It is therefore highly important that these mothers are diagnosed during pregnancy and that they have a regular postpartum follow-up for identification and treatment of any complications.

Materials and methods: All antenatal women attending the antenatal clinic (ANC) at 24-28 weeks of pregnancy were included in the study. After obtaining history, detailed examination, and informed consent, $2 \mathrm{~mL}$ of blood sample was taken in fluoride vial under all aseptic precautions in nonfasting state and after giving $75 \mathrm{~g}$ oral glucose load. Blood sugar levels were assessed in the obtained samples. All those women having blood sugar levels $>140 \mathrm{mg} / \mathrm{dL}$ were categorized as GDM as per the Diabetes in Pregnancy Study Group of India (DIPSI) criteria. Same women were called again after 3-4 days in fasting state. First, $2 \mathrm{~mL}$ of the sample was taken in fasting state and then after giving oral glucose load of $75 \mathrm{~g}$. Samples were taken after 1 and 2 hours consecutively. All those women who are having any single plasma glucose values above or equal to the cutoff, fasting: $\geq 92 \mathrm{mg} / \mathrm{dL}$, 1-hour: $\geq 180 \mathrm{mg} / \mathrm{dL}$, and 2-hour: $\geq 153 \mathrm{mg} / \mathrm{dL}$ were categorized GDM as per the International Association of Diabetes and Pregnancy Study Groups (IADPSG) criteria 6: the data so collected were subjected to the analysis using SPSS version 21; power of the study was taken as $80 \%$. Vitros GLU Slide method was used for blood sugar estimation. Chi-square test and Student's t-test were used to test the significance of two means. Level of significance was significant at $p \leq 0.05$.

Result: Sensitivity of DIPSI is quite low, hence to be used as screening and diagnostic tool at the same time is still questionable. A repeat DIPSI at 32-34 weeks may increase its sensitivity. Even if we are using DIPSI for the diagnosis of GDM, the 2-hour capillary blood glucose (CBG) cutoff should be lowered than $140 \mathrm{mg} / \mathrm{dL}$ for good sensitivity of the test.

Conclusion: Doctor's counseling and motivation are the best drives to bring mothers in fasting state and can make IADPSG too a simple and cost-effective single-step method in our country. This is the dire requirement of our country to have a better sensitive method for diagnosing GDM so that healthcare facility does not crunch out because of additional false-positive cases detected by DIPSI.

Keywords: Diabetes in Pregnancy Study Group of India, Gestational diabetes mellitus, International Association of Diabetes and Pregnancy Study Groups.

Journal of South Asian Federation of Obstetrics and Gynaecology (2021): 10.5005/jp-journals-10006-1935
\end{abstract}

\section{INTRODUCTION}

Gestational diabetes mellitus (GDM) is a glucose tolerance disorder which is diagnosed first time during pregnancy. ${ }^{1}$ GDM is significantly associated with perinatal morbidity, mortality, and maternal morbidity too. It affects $1-14 \%$ of all pregnancies, and its incidence has been increasing continuously. ${ }^{1}$

It is therefore very important that these mothers are diagnosed during antenatal visits, and they have a regular postnatal follow-up for timely diagnosis and treatment of any complications.

Diagnosis of GDM in India requires more sensitive tests as the prevalence of GDM in our country is as high as $16.55 \%$ and Indians have 11 times increased risk for the development of GDM as compared to Caucasians. Therefore, choice of test is also dependent on the ethnic race to be studied. For pregnant women in India, the Diabetes in Pregnancy Study Group of India (DIPSI) has proposed a one-step glucose challenge test by $75 \mathrm{~g}$ oral glucose for screening as well as diagnosis of GDM. According to the DIPSI recommendation/ criteria, a pregnant woman after undergoing preliminary clinical examination was given a $75 \mathrm{~g}$ oral glucose load, irrespective of the

\footnotetext{
${ }^{1-5}$ Department of Obstetrics and Gynaecology, ERA's Lucknow Medical College and Hospital, Lucknow, Uttar Pradesh, India

Corresponding Author: Shweta Kumari, Department of Obstetrics and Gynaecology, ERA's Lucknow Medical College and Hospital, Lucknow, Uttar Pradesh, India, Phone: +91 9430604966, e-mail: dr053shweta@ gmail.com

How to cite this article: Singh A, Yadav R, Kunwar S, et al. Comparative Evaluation of Diabetes in Pregnancy Study Group of India and International Association of Diabetes and Pregnancy Study Groups: Criteria for the Diagnosis of Gestational Diabetes Mellitus. J South Asian Feder Obst Gynae 2021;13(4):212-215.

Source of support: Nil

Conflict of interest: None
}

time of the last meal, and venous blood sample was collected at 2 hours for estimating plasma glucose by the glucose oxidation and peroxidation (GOD-POD) method. GDM was diagnosed if 2-hour plasma glucose is $\geq 140 \mathrm{mg} / \mathrm{dL}^{2}$ 
According to the International Association of Diabetes and Pregnancy Study Groups (IADPSG) recommendation, diagnosis of GDM is made when any of the following plasma glucose values meet or exceed $75 \mathrm{~g}$ OGTT: fasting: $\geq 92 \mathrm{mg} / \mathrm{dL}$, 1-hour: $\geq 180 \mathrm{mg} / \mathrm{dL}$, 2-hour: $\geq 153 \mathrm{mg} / \mathrm{dL}$. If fasting plasma glucose is $>126 \mathrm{mg} / \mathrm{dL}$ or $\mathrm{HbA} 1 \mathrm{C}>6.5 \%$ in the early weeks of pregnancy, then it made the diagnosis of overt diabetes. ${ }^{3}$

In the present study, we make an attempt to compare the efficacy of DIPSI in comparison with the IADPSG criteria for the diagnosis of GDM as DIPSI on one side is a simplified method and addresses logistic barriers in a low-resource country like India, but on the other side it has lower sensitivity in comparison with IADPSG. In DIPSI due to exaggerated insulin response over added glucose on the top of the previous meal leads to lower blood glucose levels leads to missing of those patients who are having fasting hyperglycemia.

\section{Materials and Methods}

This study was conducted on 160 pregnant women who visited the antenatal clinic (ANC) at 24-28 weeks of pregnancy in the Department of Obstetrics and Gynaecology, ELMC\&H, Lucknow. Informed consent was obtained from the women enrolled in this study.

After obtaining history, detailed examination, and informed consent, $2 \mathrm{~mL}$ of blood sample was taken in fluoride vial under all aseptic precautions in nonfasting state and after giving $75 \mathrm{~g}$ oral glucose load. Blood sugar levels were assessed in the obtained samples. All those women having blood sugar levels $>140 \mathrm{mg} / \mathrm{dL}$ were categorized as GDM as per DIPSI criteria.

Same women were called again after 3-4 days in fasting state, $2 \mathrm{~mL}$ of the sample was taken in fasting state and then after giving oral glucose load of $75 \mathrm{~g}$. Samples were taken after 1 and 2 hours consecutively. All those women who are having any single plasma glucose values above or equal to the cutoff, fasting: $\geq 92 \mathrm{mg} / \mathrm{dL}$, 1-hour: $\geq 180 \mathrm{mg} / \mathrm{dL}$, 2-hour: $\geq 153 \mathrm{mg} / \mathrm{dL}$ were categorized GDM as per IADPSG criteria. ${ }^{3}$

Standard management guidelines were followed for all those women diagnosed as GDM. All the women designated as GDM by either of two criteria were followed up until delivery, and maternal and neonatal outcomes were noted.

The data so collected were subjected to the analysis using SPSS version 21 , and the power of the study was taken as $80 \%$. Vitros GLU Slide method was used for blood sugar estimation. Chi-square test and Student's $t$-test were used to test the significance of the two means. Level of significance was significant at $p \leq 0.05$.

\section{Results}

Maximum number of women $(n=72 ; 45 \%)$ were aged $21-25$ years with a mean age of women $25.71 \pm 3.39$ years. More than two-thirds ( $n=110 ; 68.8 \%$ ) of women were in normal weight category. A total of 31 (19.4\%) were in overweight category and 18 (11.3\%) were in underweight category. One (0.6\%) pregnant woman was obese.

Majority of the case had no reported complications. Among various complications, hypothyroidism was found in the majority.

No significant association of GDM positivity using either of the two criteria was observed with age, BMI, hemoglobin levels, gravida, and medical history because of the homogeneity of the population as shown in Table 1.

Using DIPSI criteria, a total of 38 (23.8\%) cases were diagnosed as GDM, while using IADPSG criteria, a total of 35 (21.9\%) cases were diagnosed as GDM.

The IADPSG diagnosed 35 cases as GDM and ruled out GDM in the remaining 125 cases. On comparing the performance of DIPSI against IADPSG, DIPSI identified 13 true-positive, 25 false-positive, 22 false-negative, and 100 true-negative cases. Correspondingly, the sensitivity, specificity, positive predictive value (PPV), and negative predictive value (NPV) of DIPSI were $37.1,80,34.2 \%$, and $82 \%$, respectively, as shown in Table 2 . Overall accuracy of DIPSI against IADPSG was only $70.6 \%$; hence applying such a test as screening as well as diagnostic tool with such low sensitivity and lower accuracy, it should be tested in a multicentric trial before using in mass.

All the 60 women diagnosed as GDM by either of the two criteria were followed up till delivery. Maternal/obstetric and neonatal complications were seen in 37 (61.7\%) cases. Among different maternal/obstetric complications, cesarean delivery was the most common (48.3\%) followed by low birth weight (16.7\%), polyhydramnios (10\%), preterm labor (8.3\%), PROM and PIH $(6.7 \%$ each), recurrent UTI (3.3\%), and meconium aspiration syndrome (3.3\%). After excluding cesarean delivery as a complication, the complication rate was only $31.7 \%$ as shown in Table 3 .

Among neonatal complications, respiratory distress was observed in nine (15.5\%) cases followed by hypoglycemia (6.9\%), hyperbilirubinemia (5.2\%), neonatal sepsis (3.4\%), and hypocalcemia and polycythemia (1.7\% case each) as shown in Table 4.

Complication rate was $53.8 \%$ for cases who were positive for GDM by both DIPSI as well as IADPSG criteria. Complication rate was only $20 \%$ for those detected GDM by DIPSI criteria, whereas it was $31.8 \%$ for those diagnosed GDM by IADPSG criteria. However, DIPSI had a lower complication rate as compared to other criteria yet this difference was not significant statistically $(p=0.104)$ as shown in Table 5 .

Table 1: Association of different demographic and clinical variables with GDM by either of the two criteria

\begin{tabular}{lccc}
\hline Variable & $\begin{array}{c}\text { GDM by either of the two } \\
\text { criteria }(n=60)\end{array}$ & $\begin{array}{c}\text { No GDM by either of the } \\
\text { two criteria }(n=100)\end{array}$ & Statistical significance \\
\hline Mean age \pm SD & $25.52 \pm 3.19$ & $25.82 \pm 3.52$ & $t=0.546, p=0.586$ \\
Mean BMI \pm SD & $22.81 \pm 3.51$ & $22.03 \pm 2.57$ & $t=1.109, p=0.269$ \\
Mean Hb \pm SD & $10.77 \pm 0.88$ & $10.94 \pm 0.95$ & $t=1.109, p=0.269$ \\
Gravida & & & \\
G1 & $31(51.7 \%)$ & $41(41 \%)$ & $X^{2}=5.415, p=0.247$ \\
G2 & $11(18.3 \%)$ & $30(30 \%)$ & \\
G3 & $13(21.7 \%)$ & $21(21 \%)$ & \\
G4 & $5(8.3 \%)$ & $5(5 \%)$ & \\
G5 & $0(0 \%)$ & $0(0 \%)$ & \\
Medical history & $9(15 \%)$ & $10(10 \%)$ & $X^{2}=0.896, p=0.344$ \\
\hline
\end{tabular}


Table 2: Diagnostic efficacy of DIPSI criteria

\begin{tabular}{lccc}
\hline & \multicolumn{2}{c}{ IADPSG } & \\
\cline { 2 - 3 } DIPSI & GDM & No GDM & Total \\
\hline GDM & 13 & 25 & 38 \\
No GDM & 22 & 100 & 122 \\
Total & 35 & 125 & 160 \\
\hline SI. No. & Variable & Percentage \\
\hline 1 & Sensitivity & 37.1 \\
2 & Specificity & 80.0 \\
3 & PPV & 34.2 \\
4 & NPV & 82.0 \\
5 & Accuracy & 70.6 \\
\hline
\end{tabular}

Table 3: Pregnancy outcome of GDM cases (by either of the two criteria) $(n=60)$

\begin{tabular}{llcc}
\hline SI. No. & Outcome & No. of cases & Percentage \\
\hline \multicolumn{2}{l}{ Maternal/obstetric complications $(\boldsymbol{n}=60)$} & & \\
1 & Pregnancy induced hypertension & 4 & 6.7 \\
2 & Polyhydramnios & 6 & 10.0 \\
3 & Preterm labor & 5 & 8.3 \\
4 & Preterm rupture of membrane & 4 & 6.7 \\
5 & Recurrent urinary tract infection & 3 & 5.0 \\
6 & Cesarean delivery & 29 & 48.3 \\
7 & IUD/stillbirth & 2 & 3.3 \\
8 & Low birth weight $(<2.5 \mathrm{~kg})$ & 10 & 16.7 \\
9 & Meconium aspiration syndrome & 2 & 3.3 \\
\hline
\end{tabular}

Table 4: Neonatal outcome of GDM cases (by either of the two criteria) $(n=60)$

\begin{tabular}{|c|c|c|c|}
\hline SI. No. & Outcome & No. of cases & Percentage \\
\hline \multicolumn{4}{|c|}{ Neonatal complications $(n=58)$} \\
\hline 1 & Respiratory distress & 9 & 15.5 \\
\hline 2 & Hypoglycemia & 4 & 6.9 \\
\hline 3 & Hypocalcemia & 1 & 1.7 \\
\hline 4 & Hyperbilirubinemia & 3 & 5.2 \\
\hline 5 & Polycythemia & 1 & 1.7 \\
\hline 6 & Neonatal sepsis & 2 & 3.4 \\
\hline
\end{tabular}

\section{Discussion}

The age of women enrolled in the present study was ranged from 19 to 35 years with a mean age of $25.71 \pm 3.39$ years. Compared to the present study, Balaji et al. ${ }^{4}$ in a study at Chennai found the mean age to be 23.6 years.

In the present study, there were $72(45 \%)$ primigravida followed by 41 (25.6\%) gravida 2. A total of 34 (21.3\%) were gravida 3 and 13 (8.1\%) were gravida 4 or above. No association between parity and GDM prevalence has been reported except one study by Gopalkrishnan et al. ${ }^{5}$ which found 1-hour positivity rate to be influenced by parity.

Mean BMI in DIPSI group was $22.4 \mathrm{~kg} / \mathrm{m}^{2}$ and in IADPSG group, it was $23.57 \mathrm{~kg} / \mathrm{m}^{2}$, but no significant association was found. One study in Delhi by Vij et al. ${ }^{6}$ showed the mean BMI of $25.48 \mathrm{~kg} / \mathrm{m}^{2}$, whereas other studies have similar findings.
Table 5: Comparison of complication rate for different criteria of detection of GDM $(n=19)$

\begin{tabular}{llccc}
\hline SI. No. & Variable & Total & $\begin{array}{c}\text { No. of } \\
\text { complications }\end{array}$ & $\begin{array}{c}\text { Complication } \\
\text { rate }\end{array}$ \\
\hline 1 & Both positive & 13 & 7 & 53.8 \\
2 & DIPSI positive only & 25 & 5 & 20.0 \\
3 & IADPSG positive only & 22 & 7 & 31.8 \\
\hline
\end{tabular}

Medical disorders like hypothyroidism and hypertension and family history were reported by 19 women (11.9\%). In the present study, apart from hypothyroidism no other major medical history was noted. Similarly, Saxena et al. ${ }^{7}$ in a study at Delhi found $16 \%$ of the cases with hypothyroidism.

In the present study, we observed that DIPSI was only $37.1 \%$ sensitive as compared to IADPSG criteria. In fact, both DIPSI and IADPSG had an agreement on 13 cases only. Contrary to these findings, Seshiah et al. ${ }^{8}$ found a high concordance between DIPSI and IADPSG criteria. Herath et al. ${ }^{9}$ who observed a positivity rate of GDM similar to our study also found DIPSI criteria to be only $40.6 \%$ sensitive which is close to $37.1 \%$ as observed in the present study. One of the stated reasons for this discrepancy is the missing fasting glucose measurement in DIPSI.

The low sensitivity of DIPSI has been reported by many studies such as Mohan et al. ${ }^{10}$ and Herath et al. ${ }^{9}$ similar to the present study.

According to the study done in Bangalore by Mitra Sujoy et al., ${ }^{11} 11.97 \%$ of the subjects were diagnosed as GDM by IADPSG vs $3.94 \%$ by DIPSI; $8.43 \%$ of the patients were diagnosed by fasting values of IADPSG, out of which $27.4 \%$ needed pharmacotherapy, an assessment tool for predicting severity; and rest $3.54 \%$ diagnosed by nonfasting values of which $57.69 \%$ needed pharmacotherapy. Hence, they concluded that DIPSI has a low diagnostic rate as compared to IADPSG because it ignores fasting blood glucose levels. The similar result was also seen when Wise Instructor Need Group Support (WINGS) validated DIPSI with WHO criteria ${ }^{12}$ for the diagnosis of GDM.

The IADPSG recommendations in the early pregnancy are debatable, but at 24-28 weeks, correlation between maternal glucose and neonatal outcomes has been found. It has been endorsed by ADA $^{13}$ in 2011, and WHO in 2013 also accepted IADPSG criteria. Australian Diabetes in Pregnancy Society and even FIGO have accepted in 2015.

The other issue to be addressed with DIPSI was capillary blood glucose (CBG) testing which is again found to be having lower sensitivity than venous plasma glucose (VPG). VPG still remains the gold standard. Even though we are using DIPSI for the diagnosis of GDM, the 2-hour CBG cutoff should be lowered than $140 \mathrm{mg} / \mathrm{dL}$ for good sensitivity of the test.

Coming to ANC in fasting state is difficult in the rural setup like us as compared to counseling by the doctor regarding the need and importance of the test and motivation toward its compliance. This has been noted in the study done by Mohan et al. ${ }^{10}$ where $78.5 \%$ of the women returned back to the clinic for repeat testing in fasting state when it was done solely for the study purpose.

Overall, a total of 60 (37.5\%) cases were identified by either DIPSI or IADPSG criteria. Among different maternal/obstetric complications, cesarean delivery was most common (48.3\%) followed by low birth weight (16.7\%), polyhydramnios (10\%), 
preterm labor (8.3\%), PROM and PIH (6.7\% each), recurrent UTI (3.3\%), and meconium aspiration syndrome (3.3\%). Among neonatal complications, respiratory distress was observed in $15.5 \%$ followed by hypoglycemia, hyperbilirubinemia, neonatal sepsis, hypocalcemia, and polycythemia. These complication rates are similar to those reported for GDM cases in other series following the standard management guidelines.

\section{Strength of the Study}

Detection of GDM by either IADPSG or DIPSI was not affected by confounding factors like age, BMI, obstetric, and medical history due to homogeneous profile of women participating in the study.

\section{Weakness of the Study}

One of the limitations of the study was the lack of follow-up of cases spared by either of the two criteria and comparing their pregnancy outcome with that of GDM cases diagnosed by different screening methods. It would have helped to identify whether the complications witnessed in the present study are related to GDM alone or just chance findings. A comparative assessment against more vigorous and strict two-step criteria could also have helped to compare the efficacy of both IADPSG and DIPSI against standard criteria.

\section{Conclusion and Clinical Significance}

Sensitivity of DIPSI is quite low, hence to be used as screening and diagnostic tool at the same time is still questionable. Doctor's counseling and motivation are the best drives to bring mothers in fasting state and can make IADPSG too a simple and cost-effective single-step method in our country. This is the dire requirement of our country to have a better sensitive method for diagnosing GDM so that healthcare facility does not crunch out because of additional false-positive cases detected by DIPSI.

\section{References}

1. Corrado F, D'Anna R, Cannata ML, et al. Correspondence between first-trimester fasting glycaemia, and oral glucose tolerance test in gestational diabetes diagnosis. Diabetes Metab 2012;38(5):458-461. DOI: 10.1016/j.diabet.2012.03.006.
2. Polur H, Prasad KD, Bandela PV, et al. Diabetes in pregnancy Study group in India (DIPSI)-a novel criterion to diagnose GDM. Int J Biochem Res Rev 2016;10(1):1-6. DOI: 10.9734/IJBCRR/2016/22624.

3. Weinert LS. International Association of Diabetes and Pregnancy Study Groups recommendations on the diagnosis and classification of hyperglycemia in pregnancy: comment to the International Association of Diabetes and Pregnancy Study Groups Consensus Panel. Diabetes Care 2010;33(7):e97. DOI: 10.2337/dc10-0544.

4. Balaji V, Balaji M, Anjalakshi C, et al. Diagnosis of gestational diabetes mellitus in Asian-Indian women. Indian J Endocrinol Metab 2011;15(3):187. DOI: 10.4103/2230-8210.83403.

5. Gopalakrishnan V, Singh R, Pradeep Y, et al. Evaluation of the prevalence of gestational diabetes mellitus in North Indians using the International Association of Diabetes and Pregnancy Study groups (IADPSG) criteria. J Postgrad Med 2015;61(3):155. DOI: 10.4103/00223859.159306.

6. Vij P, Jha S, Gupta SK, et al. Comparison of DIPSI and IADPSG criteria for diagnosis of GDM: a study in a north Indian tertiary care center. Int J Diabetes Dev Ctries 2015;35(3):285-288. DOI: 10.1007/s13410014-0244-5.

7. Saxena P, Tyagi S, Prakash A, et al. Pregnancy outcome of women with gestational diabetes in a tertiary level hospital of north India. Indian J Commun Med 2011;36(2):120. DOI: 10.4103/0970-0218.84130.

8. Seshiah V, Das A, Balaji V, et al. Gestational diabetes mellitusguidelines. JAPI 2006;54:622. PMID: 16941793.

9. Herath $M$, Weerarathna TP, Umesha D. Is non fasting glucose challenge test sensitive enough to diagnose gestational diabetes mellitus? Int Arch Med 2015;8(93):1-8. DOI:10.3823/1692.

10. Mohan V, Mahalakshmi MM, Bhavadharini B, et al. Comparison of screening for gestational diabetes mellitus by oral glucose tolerance tests done in the non-fasting (random) and fasting states. Acta Diabetol 2014;51(6):1007-1013. DOI: 10.1007/s00592-014-0660-5.

11. Mitra Sujoy, Rao PS, Mukhopadhyay l, et al. Comparison of screening for gestational diabetes mellitus by IADPSG and DIPSI guidelines: importance of fasting blood glucose value its diagnosis and management. IOSR J Dent Med Sci 2017;16(3):12-15. DOI: 10.9790/0853-1603121215.

12. Alberti KG, Zimmet PZ. Definition, diagnosis and classification of diabetes mellitus and its complications. Part 1: diagnosis and classification of diabetes mellitus. Provisional report of a WHO consultation. Diabet Med 1998;15(7):539-553. DOI: 10.1002/ (SICI)1096-9136(199807)15:7<539::AID-DIA668>3.0.CO;2-S.

13. Carpenter MW, Coustan DR. Criteria for screening tests for gestational diabetes. Am J Obstet Gynecol 1982;144(7):768-773. DOI: 10.1016/0002-9378(82)90349-0. 